\title{
Commentary: The brain's response to temperature stress involves shock proteins, RNA-binding proteins and microglia-Should cardiac surgeons care?
}

\author{
Victor A. Ferraris, MD, PhD
}

From the Department of Surgery, University of Kentucky, Lexington, Ky.

Disclosures: Author has nothing to disclose with regard to commercial support.

Received for publication July 18, 2019; accepted for publication July 22, 2019; available ahead of print Sept 10, 2019.

Address for reprints: Victor A. Ferraris, MD, PhD, Tyler Gill Professor of Surgery, University of Kentucky, A301 Kentucky Clinic, 740 S Limestone, Lexington, KY 40536-0284 (E-mail: ferraris@uky.edu).

J Thorac Cardiovasc Surg 2020;159:2447-8

$0022-5223 / \$ 36.00$

Copyright $(2019$ by The American Association for Thoracic Surgery

https://doi.org/10.1016/j.jtcvs.2019.07.062

\section{WHAT ARE MICROGLIA?}

The cellular makeup of the brain is not a topic that surfaces to the consciousness of cardiac surgeons with any regularity. In fact, one might ask, why should cardiac surgeons even care about the cellular mechanisms of the brain and the nervous system? The answer has to do with neuroprotection. Some form of neuroprotection is required in most cardiac operations that require hypothermia. The exact cellular mechanisms of this hypothermic protection are largely a mystery to cardiac surgeons, but, as with everything else that we do, knowledge improves patient care and outcomes. It is therefore well worth exploring these cellular mechanisms.

The cellular components of the brain are called glia. Glial cells (also called neuroglia or simply glia) are the most abundant cells in the adult central nervous system (CNS). Astrocytes, oligodendrocytes, and microglia are subtypes of glial cells. Microglia are located throughout the brain and spinal cord, and they account for $10 \%$ to $15 \%$ of all cells found in the CNS. Microglia are the resident macrophages that act as the first and main form of active immune defense in the CNS. This immune response includes activation of an inflammatory response that typically acts to alleviate and control neuronal damage. Importantly, microglial cells remove damaged cells and cellular debris by phagocytosis.

The chronic activation of microglia may in turn cause neuronal damage through the release of potentially cytotoxic molecules, such as proinflammatory cytokines, reactive oxygen intermediates, proteinases, and certain protein cofactors. A prolonged inflammatory response is mediated by the activated microglia, and the chronic activation of microglia may in turn cause neuronal damage through the release of potentially cytotoxic inflammatory mediators. An inflammatory process in the CNS is believed to play an important role in the pathways leading to neuronal cell

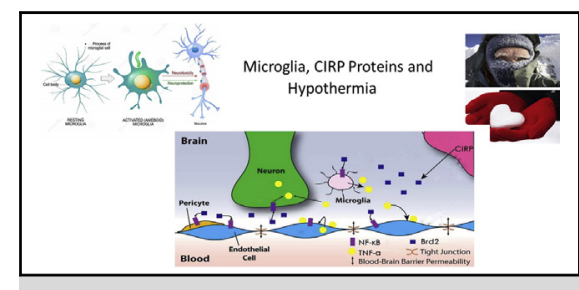

Molecular mechanisms of brain neuroprotection and neurotoxicity.

\section{Central Message}

Responses to cold stress in the central nervous system involve microglia and multiple proinflammatory mediators. Limiting harm from these mediators provides optimal DHCArelated surgical outcomes.

See Article page 2431.

death in several neurodegenerative diseases, including Parkinson disease, Alzheimer disease, prion diseases, multiple sclerosis, and HIV-related dementia.

\section{WHAT ARE THE PROINFLAMMATORY MEDIATORS OF COLD STRESS IN THE BRAIN?}

Microglia are central components to the onset and progression of inflammation in brain tissue. The maladaptive response of microglia to heat and cold stress produces an abundance of proinflammatory mediators, some of which are toxic to surrounding neurons. Animal models of cardiopulmonary bypass suggest that these toxic effects of microglia can damage neurons and worsen CNS tissue injury during deep hypothermic circulatory arrest (DHCA). ${ }^{1}$ Further, animal studies suggest that prolonged microglial activation, and ultimately microglial cell injury, in brain white matter can occur after cardiopulmonary bypass. ${ }^{2}$ This microglial damage can show up as a spectrum of neurocognitive disorders, ranging from "brain fog" 3 to major neurocognitive impairment. ${ }^{4}$ This brain-specific inflammatory response is systemically silent, and it is dependent on the brain connection fibers. Damage to these connection fibers may affect specific connectivity deficits observed after cardiopulmonary bypass. ${ }^{1}$ Functional connectivity describes the relationship of varying neural elements, and this connectivity requires integrated relationships between 
separated brain regions (eg, sensing a stimulus and then acting on that stimulus at remote sites). This integrated relationship can be damaged by various systemic stresses, including temperature stresses such as DHCA.

Suppression of microglia-mediated inflammation is likely an important strategy in neurodegenerative disease prevention and therapy. Several anti-inflammatory drugs may limit microglial activation and exert neuroprotective effects in the CNS after different types of stressors, including DHCA. The exact molecular mechanisms by which these effects occur, however, remain as targets for continuing research. ${ }^{5}$

\section{BRAIN PROTECTION DURING COLD STRESS}

The brain has protective mechanisms to deal with coldand hot-stresses. Hypothermia induces expression of important mediators, including heat shock proteins and cold-inducible RNA-binding proteins (CIRPs). ${ }^{6}$ The role of these cold-induced mediators is proving to be both protective and potentially harmful at extremes. Animal studies suggest that mild hypothermia can suppress harmful apoptosis and limit cytokine production. ${ }^{6,7}$ On the other hand, deep hypothermia may have both clinical and chemical adverse effects. ${ }^{8,9}$

In this issue of the Journal, more evidence surfaces regarding the mechanisms and importance of neuroinflammatory intermediates in brain injury patterns during and after DHCA. In their article in this issue, Liu and colleagues $^{10}$ describe a relationship between CIRP and DHCA-related cell damage. CIRP acts as a novel inflammatory mediator that stimulates the release of proinflammatory cytokines from microglia. Liu and colleagues ${ }^{10}$ used a rat model of DHCA and found that CIRP levels were elevated in rats exposed to DHCA. With rats that were genetically engineered knockout animals with absent CIRPs $\left(\mathrm{CIRP}^{-l-}\right)$, the authors studied the downstream effects of DHCA on both $\mathrm{CIRP}^{+/+}$and $\mathrm{CIRP}^{-1-}$ rats. In $\mathrm{CIRP}^{-/-}$rats, they found that histologic injury, neuropathologic scores, and microglial activation were reduced in the presence of DHCA. They used RNA sequencing analysis to identify reductions in key proinflammatory cytokines, including nuclear factor $\kappa \mathrm{B}-$ related control of cytokine production. These elegant experiments provide intriguing evidence that CIRP may be a valuable target for modulation of DHCA-related neural and other cellular injury. Much more work needs to be done before a clinical role for CIRP inhibition can be defined, but these early animal model results are a necessary first step. These mechanisms are something that will likely prove important in the future of our specialty. They have implications for all sorts of medical and surgical diseases and processes, especially those that involve management of patients subjected to temperature extremes. So, yes, cardiac surgeons should care about these mechanisms. There will undoubtedly be more relevant information in the future.

\section{References}

1. Korotcova L, Kumar S, Agematsu K, Morton PD, Jonas RA, Ishibashi N. Prolonged white matter inflammation after cardiopulmonary bypass and circulatory arrest in a juvenile porcine model. Ann Thorac Surg. 2015;100:1030-7.

2. Arrica M, Bissonnette B. Therapeutic hypothermia. Semin Cardiothorac Vasc Anesth. 2007;11:6-15.

3. Ocon AJ. Caught in the thickness of brain fog: exploring the cognitive symptoms of chronic fatigue syndrome. Front Physiol. 2013;4:63.

4. Browndyke JN, Berger M, Harshbarger TB, Smith PJ, White W, Bisanar TL, et al. Resting-state functional connectivity and cognition after major cardiac surgery in older adults without preoperative cognitive impairment: preliminary findings. J Am Geriatr Soc. 2017;65:e6-12.

5. Dheen ST, Kaur C, Ling EA. Microglial activation and its implications in the brain diseases. Curr Med Chem. 2007;14:1189-97.

6. Kaneko T, Kibayashi K. Mild hypothermia facilitates the expression of coldinducible RNA-binding protein and heat shock protein 70.1 in mouse brain. Brain Res. 2012;1466:128-36.

7. Saito K, Fukuda N, Matsumoto T, Iribe Y, Tsunemi A, Kazama T, et al. Moderate low temperature preserves the stemness of neural stem cells and suppresses apoptosis of the cells via activation of the cold-inducible RNA binding protein. Brain Res. 2010;1358:20-9.

8. Keeling WB, Tian DH, Leshnower BG, Numata S, Hughes GC, Matalanis G, et al. Safety of moderate hypothermia with antegrade cerebral perfusion in total aortic arch replacement. Ann Thorac Surg. 2018;105:54-61.

9. Weinrauch V, Safar P, Tisherman S, Kuboyama K, Radovsky A. Beneficial effect of mild hypothermia and detrimental effect of deep hypothermia after cardiac arrest in dogs. Stroke. 1992;23:1454-62.

10. Liu M, Li Y, Gao S, Yan S, Zhang Q, Liu G, et al. A novel target to reduce microglial inflammation and neuronal damage after deep hypothermic circulatory arrest. J Thorac Cardiovasc Surg. 2020;159:2431-44.e7. 